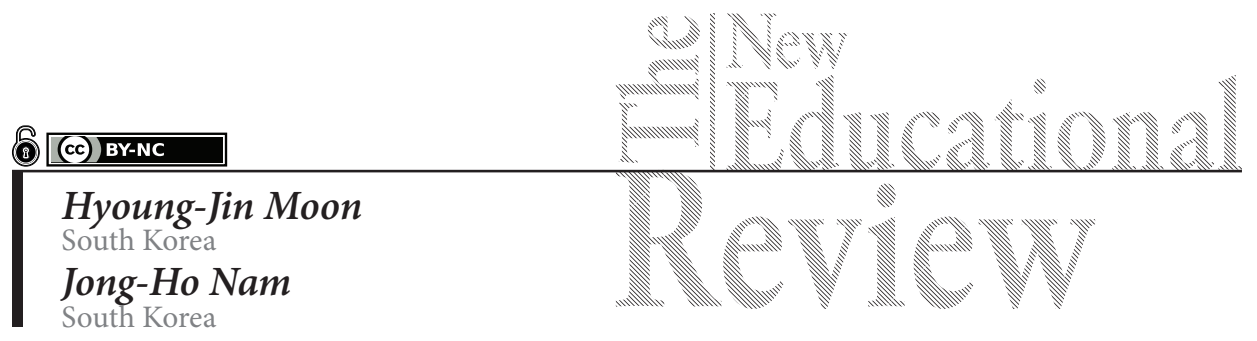

\title{
Method to Teach Korean History to Migrant Brides in Korea from China, Vietnam, and Japan'
}

DOI: $10.15804 /$ tner.2020.62.4.09

\begin{abstract}
To find a more effective teaching method, the acceptance of migrant brides from China, Vietnam, and Japan of Korean history was investigated using the survey method. Four types of teaching methods were investigated. Before participating in the survey, migrant brides from Vietnam preferred the cramming teaching method (CTM), and those from China and Japan favored an audiovisual teaching method (ATM). However, after experiencing four types of teaching methods for a week-the CTM, ATM, comparative-history teaching method (CHTM), and discussion teaching method (DTM) - participants from Vietnam indicated the highest preference for ATM, whereas those from Japan and China preferred CHTM. Ultimately, this study demonstrated that a comparative-history teaching method is most effective for teaching migrant brides from countries with a history of recurrent cultural conflicts with Korea.
\end{abstract}

Key words: history education, cramming teaching method, comparative-history teaching method, discussion teaching method, audiovisual teaching method

1 This work was supported by the Hankuk University of Foreign Studies Research Fund of 2020. 


\section{Introduction}

The number of migrant brides coming to Korea is increasing. While there were 82,828 of such women in 2006, this figure increased to 107,799 in 2008 and 137,094 in 2020 (2019 Annual Report on Korea Immigration Service, Ministry of Justice). Regarding their country of origin, China takes the lead, followed by Vietnam and Japan. For their region of residence, 53\% live in the capital area of Seoul and Gyeonggi-do, and the rest in provincial areas (e.g., Chungcheong, Jeolla, and Gyeongsang).

Fervor for education began to sweep across Korea in the 1980s. The generation of parents who did not receive a proper education was highly dedicated and determined to ensure the education of their own sons and daughters. Incidentally, female students who left home to attend school in Seoul also found employment in the capital city and settled there after graduation, which made it difficult for the unmarried men in rural areas to find future spouses. As a result, there was a large number of unmarried men in Korea's rural regions, creating a grave social issue. In response, local governments launched a large-scale campaign to marry off these unmarried men (Yonhap News Agency, 2011-10-19). International marriage swiftly flourished because of the coinciding interest of women who admired the Korean culture and hoped to move there. Moreover, local governments welcomed them to pair with unmarried local men and revitalize the collapsing rural areas.

Among neighboring countries, Koreans preferred women from countries that shared the Confucian culture (Hwang, 2002), namely China and Japan in East Asia and Vietnam in Southeast Asia. Among the women from the three countries, the Korean-Chinese from China were particularly preferred because they were able to better communicate and shared similar customs, since their parents, as emigrants from Korea, were from the same ethnic group (Lee, 1994; Han \& Gwon, 1994). In short, there was an element of convenience when living with these women. Similarly, women from Vietnam were also favored as brides because of shared Confucian customs like obedience to parents and showing respect towards men. Likewise, Korean men also liked Japanese women, who are seen as submissive and are from the same cultural sphere.

Given the aforementioned, what are the lives of these migrant brides like in Korea? Are their relations with Koreans amicable? Historically, Korea has experienced small and large clashes and conflicts with neighboring countries, and Koreans still harbor lingering resentment against people from these places. Nevertheless, women from these countries marry into Korea because of the shared 
Confucian culture. In a multicultural household, this historic problem is not something of the past, but persists into the present.

Evidently, the historical problem is becoming an important factor affecting the lives of migrant brides. In other words, sharing historical recognition with Koreans not only affects their relationship with their husbands and parents-in-law, but is also vital to their coexistence with other Koreans. Nevertheless, there is yet to be systematic history education targeted towards migrant brides in Korea. In reality, neither a specialized history textbook directed toward them nor an established systematic teaching method exists. Currently, education fails to explain how to resolve conflicts that arise between previously learned history education from home countries and Korean history education taught upon arrival.

Awareness of this problem was the starting point of this study. Sharing the same historical recognition as Koreans is an important factor in terms of leading a smooth life in Korea. For this reason, this study examined the Korean history recognition of women from the three countries that married most into Korea (China, Vietnam, and Japan) and proposed the most effective method to teach it. A quantitative survey was conducted, followed by a qualitative survey through in-depth interviews to reach a well-rounded conclusion. To identify the most effective teaching method, four teaching methods were tested on the three groups, which were divided by country of origin.

\section{Research and methodology}

There were two parts to this study. First, quantitative and qualitative surveys were conducted over a 14-day period starting on December 1, 2019. Second, another survey was conducted to investigate changes after giving lectures that employed the four teaching methods for a week. The survey participants were 99 migrant brides in Korea, who came from China, Vietnam, and Japan. To be consistent with the number of participants per country, 33 were selected from each group.

In total, 90 samples were used in the analysis. Nine surveys were excluded, as they were deemed undependable or problematic. The quantitative survey consisted of 10 items in total (general history, religion, and interrelations). For the qualitative survey, 15 women - 5 from each country - were selected for the in-depth interviews. To identify an effective teaching method, the migrant brides were given lectures using four teaching method types for a week: the cramming teaching method (CTM), audiovisual teaching method (ATM), comparative-history teaching method (CHTM), and discussion teaching method (DTM). They 
were then surveyed on the method they most preferred (Moon, Nam, \& Kim, 2014; 2017). The investigation led to the finding of meaningful outcomes.

The purpose of this study was to find a way to effectively teach Korean history to migrant brides coming to Korea. Women from the three countries were selected as the subjects of this study because of their shared commonalities of Confucian culture (Nam, Kim, \& Kim, 2016) and the history of engaging in war with Korea. Through quantitative and qualitative surveys, it was possible to identify the difficulties and problems migrant brides face when accepting the history of a foreign country. Careful attention is considered necessary when teaching history to those in a similar cultural sphere since there is a history of cultural clashes. There is also the possibility that previously learned history in their mother countries becomes an obstacle when accepting the history and culture of the target country, and past history continues into and impacts the present time.

\section{Sample: Degree of Korean history recognition}

As of 2020,137,094 migrant brides are married to Korean men, of which 86\% are from China, Vietnam, and Japan. The highest number are women from China including those who are Korean-Chinese at $44 \%(60,324)$, followed by those from Vietnam at 32\% $(44,172)$ and Japan at $10 \%(14,184)$ (Monthly Report of Korea Immigration Service (April, 2020), Ministry of Justice). In this regard, how should the women from these countries, who constitute the majority of migrant brides in Korea, be educated on Korean history? Before developing a systematic approach to education, the degree of recognition of basic Korean history was investigated with a focus on general historical knowledge, religion and culture, and relations between the two countries.

Table 1. Degree of recognition of migrant brides from the three countries of general Korean history as well as religion and culture $(n=90)$

\begin{tabular}{lrrrrrr}
\hline \multirow{2}{*}{ Category } & \multicolumn{2}{c}{ China } & \multicolumn{2}{c}{ Vietnam } & \multicolumn{2}{c}{ Japan } \\
\cline { 2 - 7 } & $\begin{array}{c}\text { Cor- } \\
\text { rect } \\
\text { answer }\end{array}$ & $\begin{array}{c}\text { In- } \\
\text { corect } \\
\text { asnwer }\end{array}$ & $\begin{array}{c}\text { Cor- } \\
\text { rect } \\
\text { answer }\end{array}$ & $\begin{array}{c}\text { In- } \\
\text { corect } \\
\text { asnwer }\end{array}$ & $\begin{array}{c}\text { Cor- } \\
\text { rect } \\
\text { answer }\end{array}$ & $\begin{array}{c}\text { In- } \\
\text { corect } \\
\text { asnwer }\end{array}$ \\
\hline 1. How long is Korean history? & $18 \%$ & $82 \%$ & $40 \%$ & $60 \%$ & $33 \%$ & $67 \%$ \\
\hline 2. Who is the finding person of China? & $24 \%$ & $76 \%$ & $59 \%$ & $41 \%$ & $61 \%$ & $39 \%$ \\
\hline $\begin{array}{l}\text { 3. What is the average length of Korean } \\
\text { dynasties? }\end{array}$ & $13 \%$ & $87 \%$ & $48 \%$ & $52 \%$ & $28 \%$ & $72 \%$ \\
\hline
\end{tabular}




\begin{tabular}{lcccccc}
\hline \multirow{2}{*}{ Category } & \multicolumn{2}{c}{ China } & \multicolumn{2}{c}{ Vietnam } & \multicolumn{2}{c}{ Japan } \\
\cline { 2 - 7 } & $\begin{array}{c}\text { Cor- } \\
\text { rect } \\
\text { answer }\end{array}$ & $\begin{array}{c}\text { In- } \\
\text { corect } \\
\text { asnwer }\end{array}$ & $\begin{array}{c}\text { Cor- } \\
\text { rect } \\
\text { answer }\end{array}$ & $\begin{array}{c}\text { In- } \\
\text { corect } \\
\text { asnwer }\end{array}$ & $\begin{array}{c}\text { Cor- } \\
\text { rect } \\
\text { answer }\end{array}$ & $\begin{array}{c}\text { In- } \\
\text { corect } \\
\text { asnwer }\end{array}$ \\
\hline $\begin{array}{l}\text { 4. What is the indigenous faith of } \\
\text { Koreans? }\end{array}$ & $19 \%$ & $81 \%$ & $41 \%$ & $59 \%$ & $20 \%$ & $80 \%$ \\
\hline 5. Who created Hangeul? & $56 \%$ & $44 \%$ & $54 \%$ & $46 \%$ & $63 \%$ & $37 \%$ \\
\hline $\begin{array}{l}\text { 6. What is the color that Koreans favor } \\
\text { the most? }\end{array}$ & $33 \%$ & $67 \%$ & $32 \%$ & $68 \%$ & $38 \%$ & $62 \%$ \\
\hline
\end{tabular}

According to Table 1, the degree of recognition of Korean history as well as religion and culture by migrant brides from the three countries was not high and the rate of correct answers varied depending on their country of origin. Those from China and Japan tended to observe Korean history from the historical viewpoint of their own countries (Kim \& Jeong, 2004; Yu, 2005), while those from Vietnam formed knowledge based on what they were taught, as the country is historically less involved than the other two countries.

Specifically, migrant brides from China had the lowest rate of correct answers (13\%) for the question on the average length of Korean dynasties. This is because no Chinese-formed dynasty survived more than 300 years during the traditional era. Furthermore, for the question on the timespan of Korea's history, they had difficulty grasping that Korea has a history of 5,000 years (including the beginning of Korea in the Dangun legend). This is because the history of their own country spans about 3,000 years. This tendency was also evident in their responses to "What is the indigenous religion in Korea?" For this, 43\% of Chinese migrant brides wrongly answered Confucianism, and only 19\% gave the correct answer: "no religion (shamanism)." Migrant brides from Japan displayed similar tendencies as their Chinese counterparts, in that they had a low rate of correct answers for questions on indigenous religion (20\%) and average length of Korean dynasties (28\%). They tended to consider as important the influence of Japan's Shintoism, their indigenous faith, in Korea during the Japanese colonial period (33\%). In addition, they had difficulty recognizing (rate of incorrect answers of $72 \%$ ) that the average length of Korean dynasties is more than 500 years, because dynasty shifts frequently occurred during the Japanese traditional era. On the other hand, unlike their Chinese and Japanese counterparts, migrant brides from Vietnam relied on learned knowledge, as their country is historically less involved than the two other countries. As a result, the women from Vietnam had a higher rate of correct answers than those from China and Japan for the four questions on 
the length of Korean history (40\%), beginning of Korea (59\%), average length of Korean dynasties (48\%), and indigenous religion (41\%).

The migrant brides from the three countries were also surveyed on the degree of recognition of the historical relation between Korea and their home country. A common question on the size of Korea's economy was also asked.

Table 2. Degree of recognition of migrant brides from the three countries of the relation between Korea and their home country $(n=90)$

\begin{tabular}{llllllc}
\hline \multirow{2}{*}{ Category } & \multicolumn{2}{c}{ China } & \multicolumn{2}{c}{ Vietnam } & \multicolumn{2}{c}{ Japan } \\
\cline { 2 - 7 } & $\begin{array}{l}\text { Correct } \\
\text { answer }\end{array}$ & $\begin{array}{c}\text { Incorect } \\
\text { asnwer }\end{array}$ & $\begin{array}{c}\text { Correct } \\
\text { answer }\end{array}$ & $\begin{array}{c}\text { Incorect } \\
\text { asnwer }\end{array}$ & $\begin{array}{c}\text { Correct } \\
\text { answer }\end{array}$ & $\begin{array}{c}\text { Incorect } \\
\text { asnwer }\end{array}$ \\
\hline $\begin{array}{l}\text { 1. When did the Korean War } \\
\text { take place? }\end{array}$ & $51 \%$ & $49 \%$ & $38 \%$ & $62 \%$ & $25 \%$ & $75 \%$ \\
\hline $\begin{array}{l}\text { 2. When did the Imjin War } \\
\text { take place? }\end{array}$ & $38 \%$ & $62 \%$ & $31 \%$ & $69 \%$ & $43 \%$ & $57 \%$ \\
\hline $\begin{array}{l}\text { 3. When did Korea become } \\
\text { involved in the Vietnam War? }\end{array}$ & $35 \%$ & $65 \%$ & $63 \%$ & $37 \%$ & $29 \%$ & $71 \%$ \\
\hline $\begin{array}{l}\text { 4. The Korean economy ranks } \\
\text { 10 }\end{array}$ & $35 \%$ & $65 \%$ & $37 \%$ & $63 \%$ & $28 \%$ & $72 \%$ \\
\hline
\end{tabular}

Based on the wars between Korea and China, Vietnam, and Japan during the traditional era, the questions provided in Table 2 investigated how migrant brides perceived the relation between Korea and their mother countries. In the case of the Korean War that started in 1950, women from China had a relatively high rate of correct answers (51\%) compared to those from Japan (25\%) and Vietnam (38\%), since the Chinese army sent soldiers on a massive scale under the pretext of "resisting America and aiding Korea" (Choi \& Moon, 2006). Regarding the Imjin War, in which Japan invaded Korea in 1592, the highest rate of correct responses was from the Japanese migrant brides (43\%). Likewise, the Korean army entered the Vietnam War (war with America in the process of unifying Vietnam, 1960-1975) as an ally of the United States, and the migrant brides from Vietnam regard it as playing an important role in the relation between Korea and Vietnam. The rate of correct responses was $63 \%$.

In-depth interviews were conducted to analyze how the migrant brides perceived the relation between Korea and their home countries, which investigated their thoughts on who caused the war, how it proceeded, and the consequences thereof. The interviews revealed that Chinese migrant brides remember the Korean War as fighting against American imperialism by supporting North Korea. The 
migrant brides from Japan also held distorted views in that "despite causing much pain during Japan's colonization of Korea for 36 years between 1910 and 1945, such as prohibiting the use of the Korean language, it also provided much support to Korea." On the other hand, the migrant brides from Vietnam were proud that their country defeated the United States and other powerful countries during the Vietnam War.

The findings of the quantitative and qualitative surveys show that the migrant brides from the three countries tended to recognize Korean history through knowledge previously acquired in their home countries. Based on the quantitative and qualitative findings of Korean history recognition by migrant brides from the three countries, a more effective teaching method was explored. Table 3 summarizes the results of the survey on the most effective teaching method from the views of the migrant brides.

Table 3. Which teaching method was most effective for you? $(n=90)$

\begin{tabular}{ll}
\hline \multicolumn{1}{c}{ Category } & $\%$ \\
\hline Cramming teaching method (CTM) & $31 \%$ \\
\hline Audiovisual teaching method (ATM) & $36 \%$ \\
\hline Comparative-history teaching method (CHTM) & $23 \%$ \\
\hline Discussion teaching method (DTM) & $11 \%$ \\
\hline
\end{tabular}

The migrant brides from the three countries chose ATM as most effective (36\%), followed by CTM (31\%), CHTM (23\%), and DTM (11\%). Table 4 summarizes the findings regarding the most preferred teaching method for each country.

Table 4. What is your most preferred teaching method? $(n=90)$

\begin{tabular}{|c|c|c|c|}
\hline Category & China & Vietnam & Japan \\
\hline CTM & $30 \%$ & $41 \%$ & $21 \%$ \\
\hline ATM & $34 \%$ & $35 \%$ & $38 \%$ \\
\hline CHTM & $25 \%$ & $10 \%$ & $34 \%$ \\
\hline DTM & $101 \%$ & $14 \%$ & $7 \%$ \\
\hline
\end{tabular}

While migrant brides from Vietnam preferred CTM, where they take in what is taught by a teacher, those from China and Japan preferred ATM for learning Korean history, which entails watching and listening to material. Since China, Vietnam, and Japan share the Confucian culture, they all indicated their different 
degrees of preference for CTM (Moon \& Nam, 2018) (Vietnam (41\%), China $(30 \%)$, and Japan (21\%)). Furthermore, the women from countries with stronger conflicting relations and cultural clashes with Korea-Japan colonized Korea for 36 years (1910-1945) and China invaded Korea several times - attempted to understand Korean history by comparing it with the history of their home country.

\section{Results: \\ The most effective teaching method}

To examine changes from the most effective and preferred teaching methods, four types of teaching methods were implemented for a week (December 15-21, 2019). The migrant brides from China, Vietnam, and Japan were divided into 3 classes in respect to their countries of origin with 30 people in each, and the 4 teaching methods were employed during all lectures for each class. For each teaching method, three topics were taught for two hours.

Specifically, for CTM, the Korean dynasties were divided into four periods: the three Kingdoms of Korea (BC 57-918), Goryeo Kingdom (918-1392), Joseon dynasty (1392-1910), and the period when Korea was under Japanese rule (19101945). The characteristics, religion, and culture of each dynasty were presented. Next, for ATM, three topics were selected - the effects of Confucianism on people's thoughts and behaviour, cases of Korea-Japan conflicts during the Japanese colonial period, and spread and acceptance of culture (e.g., Japanese animations, K-pop) - and a relevant video was shown. The migrant brides then evaluated the learning effect of the video. Furthermore, for CTM, three major historical events that took place between Korea and each of the three countries were selected: the Imjin War (Japanese invasion of Korea in 1592), Korean War (Chinese support for North Korea by sending its army when North Korea invaded the South in 1950), and Vietnam War (Korea sent its army to fight in the war). A two-hour lecture was presented on each. Last, for DTM, three topics were selected: Korean dining, housing culture, and rites of passage. Participants were required to evaluate the usefulness of the discussions.

After 24 hours of lectures over a one-week period, the participants were asked: "What is the most effective method for understanding the interrelationships between the three countries and Korean history and culture?" Table 5 provides the results for this question. 
Table 5. What is the most effective teaching method for you? $(n=90)$

\begin{tabular}{lccc}
\hline \multirow{2}{*}{ Category } & \multicolumn{2}{c}{$\%$} \\
\cline { 2 - 3 } & & $\mathbf{b}$ & $\mathbf{a}$ \\
\hline CTM & 31 & 22 \\
\hline ATM & 36 & 33 \\
\hline CHTM & 23 & 36 \\
\hline DTM & 11 & 10 \\
\hline
\end{tabular}

Note: Before the education $=\mathrm{b}$; After the education $=\mathrm{a}$

A noteworthy finding is the change in the response for the most effective teaching method compared to the time before participating in the survey. Prior to the survey, migrant brides selected ATM (36\%) as the most effective method for understanding Korean history. However, after experiencing the four types of teaching methods for one-week, they indicated CHTM as the most effective (36\%), followed by ATM (33\%). Table 6 shows the results.

Table 6. What is your most preferred teaching method? $(\mathrm{n}=90)$

\begin{tabular}{lcccccc}
\hline \multirow{2}{*}{ Category } & \multicolumn{2}{c}{ China } & \multicolumn{2}{c}{ Vietnam } & \multicolumn{2}{c}{ Japan } \\
\cline { 2 - 7 } & $\mathbf{b}$ & $\mathbf{a}$ & $\mathbf{b}$ & $\mathbf{a}$ & $\mathbf{b}$ & $\mathbf{a}$ \\
\hline CTM & $30 \%$ & $16 \%$ & $41 \%$ & $24 \%$ & $21 \%$ & $23 \%$ \\
\hline ATM & $34 \%$ & $30 \%$ & $35 \%$ & $40 \%$ & $38 \%$ & $29 \%$ \\
\hline CHTM & $25 \%$ & $35 \%$ & $10 \%$ & $30 \%$ & $34 \%$ & $42 \%$ \\
\hline DTM & $11 \%$ & $19 \%$ & $14 \%$ & $6 \%$ & $7 \%$ & $6 \%$ \\
\hline
\end{tabular}

Note: Before the education $=\mathrm{b}$; After the education $=\mathrm{a}$

This change is also apparent in the responses for the most preferred teaching method. Migrant brides from China and Japan indicated a preference for ATM prior to the survey (China (34\%), Japan (38\%)), but after the lectures, they preferred CHTM (China (35\%), and Japan (42\%)). On the other hand, Vietnamese migrant brides initially preferred CTM (41\%), but switched to ATM (40\%) after the lectures.

These findings imply that while ATM is undoubtedly an effective teaching method, as it arouses interest and is dynamic, CHTM is the more effective method when trying to understand the history of neighboring countries where historical clashes and conflicts exist. According to the level of preference for CHTM, the preference of Japanese migrant brides increased more than that of the Chinese 
(Japanese: from $38 \%$ to $42 \%$, Chinese: from $34 \%$ to $35 \%$ ), which supports the aforementioned.

When attempting to understand the history of neighboring countries, the findings of this study demonstrate that the larger the conflict between two countries, the more effective is CTM for reducing a culture clash and learning the history of a target country. The reason the women preferred CHTM was investigated to clarify its usefulness, as shown in Table 7.

Table 7. Why do you prefer the comparative-history teaching method?

\begin{tabular}{l|c}
\hline \multicolumn{1}{c|}{ Category } & $\%$ \\
\hline Identify differences & $17 \%$ \\
\hline Decrease cultural conflicts & $\mathbf{4 2} \%$ \\
\hline Expand understanding of Korean culture & $27 \%$ \\
\hline Objectively observe and understand history & $14 \%$ \\
\hline
\end{tabular}

It was found that through CHTM, the migrant brides were able to decrease the discrepancy between the historical knowledge learned in their home country and that in Korea (42\%). The teaching method also expanded their understanding of Korean culture (27\%). In short, it was demonstrated that CHTM, which points out differences between two countries, is most effective in bringing about acceptance of the history of neighboring countries.

\section{Conclusion}

This study investigated the most effective method of teaching Korean history to migrant brides from China, Vietnam, and Japan. It was shown that before participating in the survey, the women from China and Japan preferred ATM, which aroused interest, and those from Vietnam preferred CTM. However, after a week of lectures, the Chinese and Japanese migrant brides preferred CHTM. The preference of the Vietnamese migrant brides for CHTM increased most by $20 \%$.

The study found that CHTM, which mutually compares the history of two countries, was most effective for teaching the history of neighboring countries where conflicts still exist. In other words, in the cases of the three East Asian countries (Korea, China, and Japan), there were limitations to accepting the history of their neighbors because this history was taught based on nationalism-oriented narratives (Wang, 2005). 
This tendency became more apparent for countries where invasions and antagonism persisted. In the case of Korea, China, and Japan, while there were periods of cordiality, wars were frequent and there is the somber history of colonization, which made room for the subjective interpretation of criticizing the other country or emphasizing the superiority of one's own history (Kim, 2005). Furthermore, this phenomenon worsened when some politicians used history to rile the other country or educate the people as a means to further their political career. As a result, they became obstacles for the migrant brides in accepting the history of Korea.

According to the findings of this study, CTM, which is based on facts and compares the history between the home and target country, is the most effective for migrant brides in bringing about acceptance of the history of another country.

\section{References}

2020 Annual Report on Korea Immigration Service, Ministry of Justice.

Choi, Kap-soon \& Moon, Hyong-jin. (2006). Korean modern history in Chinese high school texts (1949-2003). Journal of History and Culture, 24th Edition, 392-399.

Ha, Jong-moon. (2005). Japan's conservative shift in political situation and problems of rightwing textbooks. Seoul: Koguryo Research Foundation, 259-291.

Han, Sang-bok \& Gwon, Tae-hwan. (1994). Joseon race in Yanbian, China. Seoul. Seoul National University Press, 25-35.

Hwang, Yu-bok. (2002). Shedding light on the society and culture of Joseon Race in China. Liaoning: People's Publisher, 179-197.

Kim, Ji-hoon \& Jeong, Young-soon. (2004). Korea and Korean history in recent Chinese history textbooks for middle and high schools. Research on the Modern History of China. $23,178-179$.

Kim, Han-jung. (2005). Korea, China and Japan's recognition of modern history and education. Seoul: Koguryo Research Foundation, 25-60.

Lee, Gwang-gyu. (1994). Korean-Chinese people. Seoul: Iljogak, 124-150.

Moon, Hyoung-jin, Nam, Jong-ho \& Kim, Yongdeog. (2014). New measures for the improvement of history education for Chinese students in South Korea. The New Educational Review, 37(3), 54-55.

Moon, Hyoung-jin, Nam, Jong-ho, \& Kim, Yongdeog. (2017). New measures to improve Korean culture education for Chinese Students in South Korea: Focusing on racial differences. The New Educational Review, 50(4), 146-158.

Moon, Hyoung-jin \& Nam, Jong-ho. (2018). Study on the effect of Chinese Confucian ideas on Korean youth education \& culture and teaching method - Based on the data of university students. The New Educational Review, 54(4), 51-61.

Nam, Jong-ho, Kim, Insik \& Kim, Yongdeog. (2016). Social science education offered by Chinese departments in Korean universities. The New Educational Review, 44(2), 17-18. 
Wang, Hyeon-jong. (2005). The modernization movement of three countries and their mutual recognition: A focus on middle school history textbooks of Korea, China, and Japan. Seoul: Koguryo Research Foundation, 65-110.

Yonhap News Agency. (2011). Local government of Hampyeong-gun actively looks for wives for bachelors in rural areas, 2011-10-19. https://www.yna.co.kr/view/ RPR20111019009100353?section=search

Yu, Young-tae. (2005). Perception of Korean history and Sino-centrism in Chinese university history textbooks. China's Northeast Project and the Chinese Nationalism. Seoul: Koguryo Research Foundation. 